\title{
Building Bridges Between Community Health Centers and Academic Medical Centers in a COVID- 19 Pandemic
}

\author{
Nicholas Kenji Taylor, MD, MSc, Noha Aboelata, MD, Megan Maboney, MD, \\ Timothy Seay-Morrison, EdD, LCSW, Baldeep Singh, MD, Sang-Ick Chang, MD, MPH, \\ Steven M. Asch, MD, MPH, and Jonathan G. Shaw, MD, MS
}

The threat to the public health of the United States from the COVID-19 pandemic is causing rapid, unprecedented shifts in the health care landscape. Community health centers serve the patient populations most vulnerable to the disease yet often have inadequate resources to combat it. Academic medical centers do not always have the community connections needed for the most effective population health approaches. We describe how a bridge between a community health center partner (Roots Community Health Center) and a large academic medical center (Stanford Medicine) brought complementary strengths together to address the regional public health crisis. The 2 institutions began the crisis with an overlapping clinical and research faculty member (NKT). Building on that foundation, we worked in 3 areas. First, we partnered to reach underserved populations with the academic center's newly developed CoVID test. Second, we developed and distributed evidence-based resources to these same communities via a large community health navigator team. Third, as telemedicine became the norm for medical consultation, the 2 institutions began to research how reducing the digital divide could help improve access to care. We continue to think about how best to create enduring partnerships forged through ongoing deeper relationships beyond the pandemic. (J Am Board Fam Med 2021;34:S229-S232.)

Keywords: Academic Medical Centers, Access to Health Care, Community Health Centers, Community Medicine, COVID-19, Digital Divide, Faculty, Family Medicine, Pandemics, Public Health, Telemedicine, Vulnerable Populations

\section{Introduction}

The COVID-19 pandemic and contemporaneous renewed social justice movement have caused unprecedented shifts in the US health care landscape, including an increased emphasis on public health and community outreach. Whereas academic family

This article was externally peer reviewed.

Submitted 30 April 2020; revised 24 July 2020; accepted 30 July 2020.

From the Division of Primary Care \& Population Health, Stanford University School of Medicine, Stanford, California (NKT, MM, BS, SC, SMA, JGS); Roots Community Health Center, Oakland, California (NKT, NA); Stanford Health Care, Stanford, California (TS-M); Center for Innovation to Implementation, VA Palo Alto Health Care System, Palo Alto, California (SMA); Ravenswood Family Health Center, East Palo Alto, California (JGS).

Funding: None.

Conflict of interest: None.

Corresponding author: Nicholas Kenji Taylor, MD, MSc, Stanford University, Intermountain Healthcare, Stanford, CA 94304 (E-mail: kenji.taylor@gmail.com). medicine has long led other specialties in this area, academic medical centers as a whole have not always historically followed suit. ${ }^{1}$ Because the current crisis has followed the cracks of generational health inequities affecting African Americans and other minority groups, academic medical centers have realized the need for community anchors to test, treat, and educate some of our most vulnerable and underserved populations-traditional strengths of community health centers. ${ }^{2}$ At the same time, community health centers facing the same crisis have felt their need for technical expertise, new technologies and treatments, better disease modeling, and the financial clout to obtain supplies in bulk-traditional strengths of academic medical centers. Here we describe how Stanford's Division of Primary Care and Population Health (home to both family and internal medicine) and surrounding community health centers have deepened their partnership during the current crisis. 
Community engagement is "the collaboration between institutions of higher education and their larger communities (local, regional, state, national, and global) for the mutually beneficial exchange of knowledge and resources in a context of partnership and reciprocity". ${ }^{3}$ Two years ago, our division committed to community engagement by appointing a Director of Community Partnership (JGS). We began a partnered needs exploration that included semiformal interviews and open inquiry with potential partners, exploring past experience of collaborations, areas most amenable for support, and facilitators and pain points faced in such partnerships. As a result, we created several joint academic-community clinic faculty positions as a path to engagement and to fill unmet clinical care needs for our partners, subsidized by the academic health system. Now at four different community health centers across three counties, these faculty have facilitated cross-pollination of ideas, better communication, and shared resources between the participating partners.

Roots Community Health Center (Roots) is one of those partnerships. Roots provides nonprofit clinical services focused on people of African descent in Oakland and San Jose, CA. Roots' vision since 2008 has been to counter systemic inequities and poverty through community-based care. Led by one of the authors (NA), Roots serves an average of 10,000 patients across 10 clinical sites, with 12 providers, 50 health navigators, and other staff. Services include medical and behavioral care, health navigation, workforce enterprises, housing, outreach, and advocacy. ${ }^{4}$ Greater than $90 \%$ of Roots patients are on Medicaid, and $70-80 \%$ are of African descent. Furthermore, Roots cares for several Oakland homeless encampments with an outreach team and transitional housing program. Since 2019, a Stanford family physician faculty (NKT) has practiced as both a Roots primary care clinician and as a Stanford-Intermountain primary care delivery science fellow. ${ }^{5}$ Nine months into this partnership, we are now working swiftly to build bridges that address the immediate pandemic affecting the Bay area community. These bridges broadly are testing, evidence-based resources, and research.

\section{Testing}

Testing has been limited across the country initially because of the unavailability of tests, to deficiencies in the supply chain necessary to collect and process tests, and limited capacity from the local public health departments to deploy community testing. ${ }^{6}$ Community health centers in the San Francisco Bay area and Stanford Health Care have not been immune to these challenges. Within a few weeks of the first cases of community spread in the Bay area, however, Stanford's Clinical Virology Lab was able to scale up in-house diagnostic testing and provide it through Stanford Health Care. ${ }^{7}$ These tests were turned around in less than $24 \mathrm{~h}$ with a testing capacity of more than 1,000 per day. Even with liberalized testing criteria, Stanford was not using their full testing capacity.

Roots had a small stock of test kits from commercial laboratory partners and were one of a few community health centers in the area selectively testing patients across all clinical sites. However, results were taking more than 7 days to process through these partners, particularly problematic for a patient population disproportionately impacted by chronic disease and often living in settings in which self-isolation is difficult. Eventually, laboratory partners informed Roots they were also critically short on test processing supplies and were anticipating even longer delays in results. Furthermore, the public health department in both counties were primarily focused on supporting hospitals for the potential surge in cases and contact tracing. They had not yet scaled up testing capacity in the community.

With embedded clinical-research faculty, Roots and Stanford faculty were able to quickly identify the gap and potential solution. The Stanford-Roots partnership is now actively piloting workflows for getting testing to a key vulnerable population that has not historically been served by Stanford, a predominantly well-resourced privately insured patient base. These pilots include registration and enrollment of Roots patients into Stanford's system that has built-in telehealth capacity, teaming of Roots and Stanford medical assistants to aid in enrollment and follow-up and on-site testing at Roots' drive-through sites with delivery of test swabs to be processed at Stanford as well as facilitated referral to Stanford's drive-through testing sites for those Roots patients with cars. Through these initial testing channels and other laboratory partners, Roots has tested approximately 3,500 patients at the time of this writing and $14-16 \%$ are positive.

\section{Evidence-Based Resources}

Communication at the national, state, and local levels has been variable and rapidly changing, which has led 
to confusion, disorganization, and delays in coordinating response efforts. As a result, it has been difficult for health delivery systems including community health centers to keep up with the latest recommendations and developments in prevention, access to care, testing, and surge capacity planning without in-house expertise and dedicated human resources to sift through the deluge of COVID-19 updates. Academic institutions such as Stanford, on the other hand, have more capacity to generate the most up-to-date evidencebased practice guidelines, return to work policies, personal protective equipment guidance, and testing algorithms tailored to addressing the regionally specific COVID-19 situation.

The Roots-Stanford partnership has led to both information sharing via Stanford-Roots faculty, sharing of daily COVID-19 email updates and electronic patient resources, access to COVID-specific live and recorded Medicine grand rounds, and both formal and informal curbside consultations for clinical and operational questions between primary care leadership in each organization. With these additional resources and dedicated timely technical support that was missing from the public health department, Roots has been pivotal in reaching historically vulnerable, disproportionately impacted populations. ${ }^{8}$ Roots has not only been able to disseminate information to staff, who are often members of the East Oakland community, but also has been able to provide outreach to a large African-American community about best practices for prevention and dispel misinformation through the Roots network of health navigators. ${ }^{9}$

\section{Research}

The COVID-19 pandemic is changing many facets of how we do science- the pace, singular focus, and tangible connection to real-world consequences. ${ }^{10}$ This crisis has accelerated the urgency felt among communities of color served by Roots to be included in and have access to the treatments, devices, and technology as family members and close friends are ravaged by this virus. Stanford also feels the imperative of developing solutions and disseminating data that are most widely generalizable and inclusive of the diversity of this country.

The alignment of goals is leading to rapidly forming relationships around innovation between Stanford and Roots. Stanford, as part of its Precision Health focus, was piloting wearable devices among the Stanford Health Care community to monitor both health care workers and patients under investigation for COVID. ${ }^{11}$ Roots was looking for a way to more closely monitor outreach staff who were providing services to homeless encampments in Oakland and also to residents of a transitional housing program in which recently homeless families are living in close quarters. Stanford and Roots are coming together to quickly develop plans to implement these wearables in different groups to understand how this technology can be leveraged across a diverse set of use cases to support the needs of particularly vulnerable populations during the pandemic. In addition, leveraging Stanford's demonstrated rapid survey research capabilities around COVID, Roots is working with Stanford to develop and disseminate a needs assessment specifically for underserved communities during the COVID pandemic. The data collected from the survey will be rapidly fed back to many community-based organizations for planning purposes and policy advocacy. Lastly, in response to increased national readiness to address racism role in health inequity, Roots is exploring collaboration in qualitative research with Stanford's Presence team-an interdisciplinary team focused on the art and science of human connection-to identify practices that can promote antiracism in clinical practice.

As these research relationships quickly unfold, the sustainability of beneficial activities still needs to be addressed.

\section{Conclusion}

The threat posed by the COVID-19 pandemic is, at its core, a population health problem. Furthermore, early data suggest it impacts underserved communities like the African-American population disproportionately. ${ }^{12}$ As primary care clinicians, addressing this population health problem requires us all to think beyond traditional relationships and rapidly build bridges that leverage the strengths of academic medical institutions and community health centers, particularly as public health departments scale to fill these gaps. Through a primary care partnership that bridges those two worlds, we are learning how our institution can and should partner nimbly to address the pandemic across multiple domains-testing, evidence-based resources, and research. As with the Roots-Stanford partnership, having shared and embedded faculty is a key component of deepening these relationships. 
The pandemic and its effects will last well beyond weeks or months. Partnerships forged in response to the current crisis can lay the foundation for sustainable deep relationships beyond the pandemic, positioning us to more effectively address longstanding disparities.

To see this article online, please go to: http://jabfm.org/content/ 34/Supplement/S229.full.

\section{References}

1. Michener L, Cook J, Ahmed S. M, Yonas M. A, Coyne-Beasley T, Aguilar-Gaxiola S. Aligning the goals of community-engaged research: why and how academic health centers can successfully engage with communities to improve health. Academic Medicine 2012;87:285-291.

2. Ahmed S. M, Neu Young S, DeFino M. C, Franco Z, Nelson D. A. Towards a practical model for community engagement: Advancing the art and science in academic health centers. Journal of Clinical Translational Science, 1, 2017;310-5.

3. Millett G. A, Jones A. T, Benkeser D. Assessing differential impacts of COVID-19 on Black communities. Ann Epidemiol. 2020 Jul;47:37-44.

4. Roots Community Health Center (2020) Retrieved from https://rootsclinic.org/history/.

5. Stanford-Intermountain Fellowship (2020). Retrieved from http://med.stanford.edu/pcph/research/stanford intermountainfellowship.html.
6. Shear M, Goodnough A, Kaplan S, Fink S, Thomas $\mathrm{K}$, Weiland N. The lost month: How a failure to test blinded the U.S. to Covid-19. New York Times. Retrieved from https://www.nytimes.com/2020/ 03/28/us/testing-coronavirus-pandemic.html.

7. Conger K. Stanford provides coronavirus testing to hospitals in Bay Area and beyond. Stanford Medicine New Center. Retrieved from https://med.stanford. edu/news/all-news/2020/03/stanford-provides-covid19-testing-to-bay-area-hospitals.html.

8. Allday E. Why the coronavirus is surging in Alameda County. San Francisco Cbronicle. Retrieved from https://www.sfchronicle.com/bayarea/article/ Why-the-coronavirus-is-surging-in-Alameda-County15305913.php.

9. Geldsetzer P. Knowledge and perceptions of COVID-19 among the general public in the United States and the United Kingdom: A cross-sectional online survey. Ann Intern Med. 2020;173(2):157-160.

10. Apuzzo M, Kirkpatrick DD. Covid-19 changed how the world does science, together. New York Times. Retrieved from https://www.nytimes.com/ 2020/04/01/world/europe/coronavirus-scienceresearch-cooperation.html.

11. Mahoney M. R, Asch S. M. Humanwide: a comprehensive data base for precision health in primary care. Annals of Family, 2019;17:273.

12. Stafford K, Hoyer M, Morrison M. Outcry over racial data grows as virus slams black Americans. AP News. Retrieved from https://apnews.com/71d952faad4a2a5 d14441534f7230c7c. 